\title{
O USO DE SITUAÇÕES-PROBLEMA COMO INSTRUMENTO METODOLÓGICO EM UMA PESQUISA QUALITATIVA NO CAMPO DA FORMAÇÃO DE PROFESSORES ${ }^{1}$
}

El uso de situaciones problemáticas como instrumento metodológico en una investigación cualitativa en el campo de la educación del profesorado

The use of problem-solving situations as a methodological tool in a qualitative research in the field of teacher education

Mariana Costa Lopes da Silva* Júlio Emílio Diniz-Pereira **

https://doi.org/10.38117/2675-181X.formov2020.v2i2n4.520-536

\section{RESUMO}

Iniciou-se, na década de 80, nos Estados Unidos e no Canadá, o movimento reformista da formação de professores da educação básica que buscou refletir sobre a profissionalização do trabalho docente. Esse movimento se espalhou nos países de cultura anglo-saxônica, na Europa francófona, como também em vários países latino-americanos. Alguns princípios em comum foram: compreender o ensino como uma atividade profissional apoiada em um repertório de conhecimentos, conceber a prática profissional como um lugar de formação e produção de saberes pelos práticos e estabelecer ligação entre as instituições universitárias de formação e as escolas da educação básica. Analisaremos, neste artigo, a relevância desses princípios para o campo de pesquisa sobre formação de professores e o caminho metodológico percorrido na pesquisa "Saberes docentes e estratégias de ensino: as trocas entre professoras do ensino fundamental".

PALAVRAS-CHAVE: Formação de professores; pesquisa; metodologia; situações-problema.

\footnotetext{
1 Uma versão anterior deste texto foi publicada, na forma de capítulo de livro, em SILVA e DINIZPEREIRA (2017).
} 


\section{RESUMEN}

En la década de 1980, en los Estados Unidos y Canadá, comenzó el movimiento reformista para la formación de maestros de educación básica, buscando reflexionar sobre la profesionalización del trabajo docente. Este movimiento se extendió en los países de la cultura anglosajona, en la Europa francófona, así como en varios países de América Latina. Algunos principios comunes fueron: entender la enseñanza como una actividad profesional basada en un repertorio de conocimientos, concebir la práctica profesional como un lugar de formación y producción de conocimientos por parte de los profesionales y establecer un vínculo entre las instituciones universitarias de formación y las escuelas de educación primaria. En este artículo, analizaremos la relevancia de estos principios para el campo de la investigación sobre la educación del profesorado y el camino metodológico tomado en la investigación "Enseñar conocimiento y estrategias de enseñanza: los intercambios entre los profesores de primaria".

PALABRAS CLAVE: Formación del profesorado; investigación; metodología; situaciones problemáticas

\section{ABSTRACT}

In the 1980, the reformist movement for teacher education, with began in the United States and Canada, sought to reflect on the professionalization of teaching work. This movement spread in countries of Anglo-Saxon culture, in French-speaking Europe, as well as in several Latin American countries. Some common principles, among others, were: to understand teaching as a professional activity that can be supported by a repertoire of knowledge, to conceive professional practice as a place of training and production of knowledge by practitioners and to establish a connection between university institutions of teacher education and schools. In this article, we will analyze the relevance of these principles to the field of research on teacher education and the methodological path taken in the research "Teaching knowledge and teaching strategies: exchanges between elementary school teachers".

KEYWORDS: Teacher education; research; methodology; problem-solving.

\section{Introdução}

Este artigo, que integra dossiê temático "Pesquisas sobre Formação de Professores", baseia-se em alguns aspectos do caminho metodológico percorrido na pesquisa "Saberes docentes e estratégias de ensino: as trocas entre professoras do ensino 
O USO DE SITUAÇÕES-PROBLEMA como instrumento metodológico em uma pesquisa qualitativa no campo da Formação de professores

fundamental" "2. Em outra publicação (DINIZ-PEREIRA, 2014), tive a oportunidade de discutir o campo da pesquisa sobre a formação de professores e, desta vez, a ideia é compartilhar um texto em que refletimos sobre os desafios práticos que enfrentamos como pesquisadoras/es desse campo ao investigarmos o complexo fenômeno da preparação dos profissionais da educação básica.

Antes disso, porém, retomemos os princípios do movimento reformista da formação de professores da educação básica que se iniciou, na década de 1980, nos Estados Unidos e no Canadá, e que buscou refletir sobre a profissionalização do trabalho docente naqueles países. Como sabemos, esse movimento se espalhou nos países de cultura anglo-saxônica, na Europa francófona, como também em vários países latinoamericanos (TARDIF, 2000). Alguns princípios em comum, entre outros, foram: compreender o ensino como uma atividade profissional que pode ser apoiada em um repertório de conhecimentos, conceber a prática profissional como um lugar de formação e produção de saberes pelos práticos e estabelecer ligação entre as instituições universitárias de formação e as escolas da educação básica. Discutiremos brevemente esses princípios a seguir.

\section{Compreender o ensino como uma atividade profissional que pode ser apoiado em um repertório de conhecimentos}

Segundo Nóvoa (1995), o trabalho docente caminha para a profissionalização ${ }^{3}$. A etapa na qual o modelo de professor era do religioso e do vocacionado foi ultrapassada, mas o estatuto de profissional ainda não foi atingido plenamente, como ocorreu com profissões já estabelecidas como, por exemplo, Medicina, Direito e Engenharia. Gauthier e colaboradores (2006) afirmam que os professores hoje exercem apenas um ofício e não uma profissão, ou ainda, segundo Enguita (1991), o magistério trata-se de uma semiprofissão. Enguita (1991) defende a ideia de que, por um lado, a hierarquização da organização escolar, a padronização dos programas de ensino e dos currículos escolares contribuem para uma redução da autonomia docente no processo educacional, o que aproxima os docentes dos trabalhadores proletários, trabalhadores assalariados desprovidos dos meios de produção e que perdem o controle sobre os meios, o objetivo e o seu processo de trabalho. Por outro lado, a qualificação necessária para o desenvolvimento da atividade os aproxima dos profissionais, que são caracterizados pela

\footnotetext{
2 Trata-se de uma pesquisa realizada na Escola de Educação Básica e Profissional da UFMG - Centro Pedagógico (CP) cujos objetivos foram identificar quais saberes são trocados entre professoras dos anos iniciais do Ensino Fundamental, identificar momentos de troca de saberes entre as professoras, realizar um diálogo entre os saberes docentes e pesquisas científicas e organizar um repertório dos saberes docentes levantados.

3 Uma discussão mais crítica sobre esse processo de profissionalização da profissão docente e mais contextualizada ao contexto de países da América Latina pode ser encontrada em Coelho e Diniz-Pereira (2017).
} 
autonomia e controle sobre o seu processo de trabalho. Enfim, os docentes encontram-se neste lugar intermediário entre a profissionalização e a proletarização, ou seja, um semiprofissional.

De acordo com Gauthier et al. (2006), existem duas tendências que dificultam a profissionalização do magistério: a ideia de um ofício sem saberes e de saberes sem um ofício. Várias são as crenças que, de alguma maneira, interpretam o ofício de professor como um ofício sem saberes, ou seja, que é suficiente conhecer o conteúdo a ser ensinado, ter talento, ter bom senso, seguir a intuição, ter experiência e ter cultura. No que diz respeito ao ensino dos anos iniciais do ensino fundamental, somam-se a esses elementos a crença de que é preciso ser mulher para poder cuidar e ser carinhosa com as crianças.

Existe também a tendência de se pensar em saberes sem um ofício, no qual "o saber científico sobre o ensino tivesse amputado de seu objeto real: um professor, numa sala de aula, diante de um grupo de alunos que ele deve instruir e educar de acordo com determinados valores" (GAUTHIER et al. 2006, p. 27). O autor nos convoca a pensar em um ofício feito de saberes, na formalização dos saberes necessários para ensinar e na organização destes em um repertório. A pesquisa "Saberes docentes e estratégias de ensino: as trocas entre professoras do ensino fundamental" buscou contribuir para a constituição de parte desse repertório uma vez que investigou os saberes trocados entre oito professoras dos anos iniciais do ensino fundamental.

\section{Conceber a prática profissional como um lugar de formação e de produção de saberes pelos práticos e estabelecer ligação entre as instituições universitárias de formação e as escolas da educação básica}

A dissociação entre teoria e prática nos cursos de formação de professores é uma preocupação antiga, recorrente e atual, detectada por Diniz-Pereira (2006) em pesquisas educacionais no Brasil, pelo menos desde a década de 1980. Essa dissociação polariza e distancia a prática pedagógica da teoria e a teoria da prática. Nessa polarização cabe à academia a produção de novos conhecimentos enquanto a prática seria o lugar de aplicação das teorias e técnicas científicas produzidas nas universidades.

Fiorentini e Souza Melo (1998) explicam que, até a década de 1970, a formação de professores priorizava o conhecimento das disciplinas lecionadas, as questões pedagógicas eram pouco valorizadas. Nessa década, período do assim chamado "tecnicismo" no Brasil, eram valorizadas, então, as tecnologias de ensino, o planejamento, a organização, o controle e a avaliação em detrimento dos conteúdos de ensino. Na década de 1980, pesquisas sobre o ensino e a formação de professores priorizavam o estudo de aspectos políticos e pedagógicos. Segundo Fiorentini e Souza Melo (1998), os saberes escolares eram pouco valorizados e raramente problematizados ou investigados. Nesse período, as práticas pedagógicas de sala de aula e os saberes 
O USO DE SITUAÇÕES-PROBLEMA como instrumento metodológico em uma pesquisa qualitativa no campo da Formação de professores

docentes começaram a ser investigados, mas não com o intuito de explicitá-los e/ou valorizá-los, pelo contrário, destacavam a negatividade da prática pedagógica explicitando suas carências e comparando-os a um modelo teórico idealizado.

Para esses autores, a dicotomia teoria (o saber científico) versus prática (os saberes docentes) é "decorrente de uma cultura profissional marcada pela racionalidade técnica que supervaloriza o conhecimento teórico ou pelo pragmatismo praticista ou ativista que exclui a formação e a reflexão teórica e filosófica" (FIORENTINI e SOUZA MELO, 1998, p. 311).

A tendência que fundamenta as pesquisas sobre os saberes docentes afasta-se do modelo da racionalidade técnica na medida em que centraliza a atuação do professor buscando identificar a produção e mobilização de seus saberes. A concepção de que o professor é um técnico que transmite os conhecimentos produzidos por outros é trocada pelo reconhecimento de que os docentes produzem saberes nos contextos em que atuam. Mas Zeichner (1998) assegura que "a idéia de tratar seriamente o conhecimento produzido pelos professores como um conhecimento educacional a ser analisado e discutido é uma idéia que ainda ofende a muitos e que traz sérias consequências para quem assim procede na academia" (1998, p.234). Pesquisadores acadêmicos mostram-se relutantes em reconhecer e utilizar o conhecimento que os professores vêm gerando para informar seus próprios trabalhos na academia. Por um lado, o uso de uma linguagem especializada no meio acadêmico afasta os professores que atuam na educação básica das pesquisas acadêmicas, por outro lado, quanto mais abstrato a linguagem da pesquisa, maior é seu status na hierarquia acadêmica e quanto mais útil e aplicável menor é seu status (Somerkh apud ZEICHNER, 1998).

Segundo Zeichner (1998), tanto pesquisadores acadêmicos quanto professores ignoram as pesquisas realizadas pelo outro. Na maioria das vezes, percebem as perguntas de investigação de um e de outro como irrelevantes. Entre as razões descritas por Zeichner (1998) para a falta de entusiasmo dos professores pela pesquisa acadêmica educacional estão a frequência com o qual eles se vêem descritos de forma negativa e o baixo índice de retorno dos resultados das pesquisas para a escola.

Ainda no campo da formação de professores, Diniz-Pereira (2006) afirma que a relação entre as universidades e as escolas de educação básica tem sido um importante tema em discussão, no campo educacional brasileiro, desde o final da década de 1990, em função das mudanças na estrutura jurídico-legal no País. Entretanto, no seio das universidades, as atividades de formação de professores continuam desprestigiadas em comparação com as atividades de pesquisa. Dedicar-se à formação de docentes pode até acarretar, para os professores universitários, uma reputação inconveniente na medida em que os afasta de atividades de pesquisa (Lüdke apud DINIZ-PEREIRA, 2006). Quando o 
pesquisador universitário se interessa pela temática da escola e dos professores, seu status, em geral, torna-se menor.

Relatamos acima como o distanciamento entre universidade e escolas, professores acadêmicos e professores que atuam na educação básica, acontece em diversos níveis. $\mathrm{Na}$ pesquisa relatada neste artigo, buscamos, por meio da investigação acadêmica, constituir um espaço de colaboração entre universidade e escola na medida em que aproximamos e articulamos "os conhecimentos produzidos pelas universidades a respeito do ensino e os saberes desenvolvidos pelos professores em suas práticas cotidianas" (TARDIF, 2002, p. 23).

\section{Estratégias metodológicas}

Para atingirmos os objetivos propostos na pesquisa qualitativa "Saberes docentes e estratégias de ensino: as trocas entre professoras do ensino fundamental" dividimos a trajetória metodológica em três passos: 1 - Inserção da pesquisadora no locus da pesquisa (estudo exploratório); 2 - Grupo focal e 3 - Tratamento e análise dos dados.

\section{Inserção da pesquisadora no locus da pesquisa (estudo exploratório)}

Recém-formada em Pedagogia, trabalhei como professora substituta de Português e Matemática no Primeiro Ciclo de Formação Humana na Escola de Educação Básica e Profissional - Centro Pedagógico - da Universidade Federal de Minas Gerais (CP/UFMG), nos anos de 2006 e 2007. Experiências das professoras pertencentes ao Núcleo Básico (responsável pelas disciplinas de Matemática e Português no Primeiro Ciclo) acumuladas por meio da prática em sala de aula, foram se constituindo parte essencial da minha prática pedagógica. Experiências trocadas entre pares, pelos que exercem a profissão e conhecem o seu dia-a-dia, os pequenos detalhes que fazem tanta diferença, as dificuldades da prática educativa democrática que busca a autonomia dos alunos e dos profissionais, o preparo das aulas, a construção das "rotinas", enfim, saberes que não são documentados em livros didáticos ou aprendidos no curso de graduação.

Percebi que estava vivenciando o que um recém-formado do curso de Medicina chamaria de sua "residência": um mergulho na vida real, no dia-a-dia de sua profissão. As professoras com as quais eu trabalhava estavam à disposição para trocar ideias, tirar dúvidas e esse ambiente formador era potencializado pelas reuniões semanais de formação e discussão. Durante esse tempo realizei um registro informal dessas trocas e isso permitiu que eu, posteriormente, elaborasse as assim chamadas "situaçõesproblema". 
O USO DE SITUAÇÕES-PROBLEMA como instrumento metodológico em uma pesquisa qualitativa no campo da Formação de professores

\section{Grupo focal}

O lugar de professora permitiu que eu estivesse presente em diversos momentos de trocas de experiências, conselhos, sugestões e ideias entre as professoras. Quando essas trocas eram importantes para minha prática de professora iniciante, eu as registrava em forma de verbalização - um enunciado oral. Essas verbalizações não foram utilizadas enquanto dados para pesquisa, mas sim como elementos para uma discussão posterior. Reconhecemos que o uso desses registros é enviesado pelo olhar da professora iniciante, mas percebemos que tal viés tem seu aspecto positivo. Por meio do olhar de uma professora iniciante, conhecimentos que faziam falta para sua prática pedagógica foram evidenciados, o que para outros profissionais que não estão nessa condição poderia passar despercebido.

Os registros foram reorganizados de acordo com problemas reais relatados pelas professoras do Núcleo Básico e vivenciados pela pesquisadora na prática pedagógica. A junção do problema às verbalizações é o que passamos a denominar "situaçõesproblema". A elaboração das situações-problema foi em si um desafio, pois elas teriam a importante função de despertar discussões entre as professoras e, consequentemente, criar um espaço significativo de trocas entre as docentes. É importante ressaltar que várias vezes durante as discussões as professoras reafirmaram a importância de discutir aquelas questões. Essas falas espontâneas demonstram que não há soluções simples para as questões, nem para as professoras iniciantes ou para as experientes.

Dado a limitação do tempo de pesquisa, as situações-problema referentes ao ensino de Português e Matemática não foram utilizadas, optamos por esse recorte para delimitarmos nosso escopo de pesquisa. O primeiro semestre foi marcado pela reorganização das verbalizações em situações-problema e o retorno destas para o grupo de docentes do Núcleo Básico do $\mathrm{CP}$, do qual a pesquisadora já não fazia parte como professora.

A pesquisadora solicitou participar de uma reunião de Núcleo por mês e esclareceu sucintamente os objetivos da investigação. Os participantes não receberam as situações-problema de antemão para conhecimento, para que não viessem para as reuniões com ideias pré-formadas ou com sua participação preparada. "Saber com antecedência precisamente o que se vai discutir - por exemplo, as questões que o moderador irá colocar, ou o roteiro - propicia a formação de opiniões prévias que podem interferir nas discussões" (GATTI, 2005, p. 23).

Cada situação-problema foi enumerada e separada em cartelas diferentes de modo que as professoras teriam contato com uma situação-problema por vez. Antes de iniciarmos a coleta de dados, tínhamos como hipótese que essa estratégia metodológica propiciaria um momento de formação para as professoras, que teriam a oportunidade de 
retornar a um assunto e discuti-lo com mais tempo e tranquilidade, hipótese esta que durante a coleta de dados foi confirmada.

As situações-problema e as verbalizações a elas agregadas eram baseadas em fatos reais e este fato ajudou a propiciar discussões animadas. As professoras discordavam entre si, faziam perguntas, expressavam opiniões... "Há uma reelaboração de questões que é própria do trabalho particular do grupo mediante as trocas, os reasseguramentos mútuos, os consensos, os dissensos, e que trazem luz sobre aspectos não detectáveis ou não reveláveis em outras condições" (GATTI, 2005, p. 14).

As reuniões para coleta de dados ocorreram no horário normal dos encontros do Núcleo, mas com o objetivo específico de coletar informações para a pesquisa, sendo que as professoras já estavam avisadas que as reuniões seriam utilizadas para esse fim. $\mathrm{O}$ papel da pesquisadora nessas reuniões foi de apresentar resumidamente o objetivo da pesquisa na primeira reunião e introduzir as situações-problema, animar e direcionar a discussão, quando necessário, o que, na verdade, aconteceu poucas vezes. Organizamos as situações-problema inicialmente sem ideia de quanto tempo a discussão de cada uma levaria. Após a primeira reunião, percebemos que a discussão levaria aproximadamente uma hora para cada situação-problema. Foram discutidas duas situações-problema por reunião. Ao todo nos encontramos três vezes.

Essa estratégia metodológica aproxima-se do instrumento de pesquisa denominado "Grupo Focal", definido por Gatti (2005) como um conjunto de pessoas reunidas para discutir e comentar um tema, o objeto de pesquisa, a partir de sua experiência pessoal. Ressaltamos que o grupo não foi selecionado pela pesquisadora, mas existia previamente. Todavia, a composição do grupo atende as recomendações de Gatti (2005) por ter uma constituição baseada em características homogêneas dos participantes (todas trabalham na mesma escola, no mesmo ciclo escolar), mas com suficiente variação entre eles para que apareçam opiniões diferentes ou divergentes (são professoras em diferentes estágios da carreira profissional, desde iniciantes até professoras experientes, com diferentes graus de formação: nível superior e mestres). As recomendações de Gatti (2005) encontram respaldo na afirmação de Verloop (2001):

Dado o fato que o saber docente é por definição um saber localizado no contexto pessoal dos professores, faz sentido focalizar a busca por um saber docente compartilhado em grupos de professores que estão em uma situação similar quanto ao conteúdo ensinado, nível de escolarização e idade dos alunos ensinados (VERLOOP et al., 2001, p. 448). [Tradução nossa]

Nesse instrumento metodológico, a ênfase recai sobre a interação dentro do grupo e não em perguntas e respostas entre moderador e membros do grupo, o que o diferencia da entrevista coletiva. O foco está na interação dos participantes do grupo que discutem 
O USO DE SITUAÇÕES-PROBLEMA como instrumento metodológico em uma pesquisa qualitativa no campo da Formação de professores

um assunto, fazendo perguntas um para o outro e trocando informações. O pesquisador propõe o tema da discussão, anima e direciona a discussão quando necessário, mas os participantes têm liberdade para fazer perguntas um para o outro, de complementar e esclarecer sua opinião, de concordar ou discordar de uma posição.

"O marco das pesquisas com grupos focais é o uso explícito das interações do grupo para gerar dados e opiniões que seriam menos acessíveis sem a interação encontrada no grupo" (MORGAN, 1997, p. 2). Os grupos focais são particularmente úteis para compreender diferenças e divergências, contraposições e contradições e explorar o grau de consenso sobre um certo tópico. A pesquisa com grupos focais além de ajudar na obtenção de perspectivas diferentes sobre uma mesma questão, permite também a compreensão de ideias partilhadas por pessoas no dia-a-dia. Todas essas características são positivas para o objeto desta pesquisa.

As reuniões para coleta de dados transcorriam da seguinte maneira: cada professora tinha em mãos uma cópia da situação-problema a ser discutida e esta era lida em voz alta por uma professora. Logo em seguida, iniciava-se a discussão em torno da situação-problema e dos registros, sem obedecer a uma ordem específica. As professoras participavam espontaneamente, cada uma apresentando seu ponto de vista, suas intervenções e exemplificando. Ficou evidente que as situações-problema escolhidas eram situações-problema que faziam parte do dia-a-dia das professoras, pois estas participavam com muito interesse. Todas as reuniões foram gravadas em áudio e posteriormente transcritas.

Gatti (2005) explica que as interações no grupo e a manifestação de divergências levam as pessoas a argumentarem e explicarem sua ideia e forma de pensar. O sentido de cada ponto de vista precisa ser procurado nos próprios sentidos que o participante do grupo construiu, pelo tipo de argumentação ou explanação que faz. Por isso é importante observar detalhada e cautelosamente o que os participantes contam uns aos outros, fatos, histórias e situações.

Após a exaustão da primeira situação-problema, passávamos para a leitura da segunda situação-problema e assim esgotava-se o tempo da nossa reunião e marcávamos a próxima. O clima de cada reunião era de muito interesse pelas situações-problema em discussão. Mais de uma vez, percebi que as professoras anotavam o que a outra dizia, ou isso era expresso por meio de falas: "Vou tentar isto que você falou". Uma professora comentou que gostaria de utilizar as situações-problema no curso de formação de professores que ministrava. Esse instrumento metodológico foi planejado com o intuito de iniciar e animar uma discussão para troca, aprofundamento e detalhamento das verbalizações, onde possíveis saberes docentes seriam objetivados. Para Gauthier e colaboradores (2006), os julgamentos dos colegas de profissão e a confrontação dos pontos de vista é essencial para a validação dos saberes: 
Um repertório de conhecimentos do ensino não pode assim se reduzir à simples compilação das práticas pedagógicas, mas deve ser constituído de saberes, de conhecimentos e de julgamentos dos professores que foram submetidos a uma validação científica (...) Essa validação pode ser feita de muitas maneiras: (...) através dos julgamentos dos colegas de profissão e da confrontação dos pontos de vista. Em todos os casos, entretanto, a experiência deve abandonar o seu caráter privado e passar para o domínio público para ser examinada, analisada e criticada. (GAUTHIER et al., 2006, p. 303)

As entrevistas individuais e semiestruturadas foram organizadas em torno de questões sobre a trajetória profissional dos sujeitos da pesquisa. As entrevistas foram realizadas no próprio espaço escolar, durante o período da manhã, atendendo à disponibilidade das professoras e foram realizadas com o intuito de caracterizar os sujeitos participantes da pesquisa, o que favoreceu uma melhor compreensão e interpretação dos dados.

\section{Tratamento e análise dos dados}

Elaboramos um processo de análise dos dados, por meio do qual buscamos identificar os saberes docentes. O caminho que especificamos a seguir é uma redução da realidade, construído para fins de análise dos dados, pois percebemos em diversos momentos na fala das professoras a influência de teorias e conhecimentos científicos que serviam para modificar e/ou fundamentar seus argumentos práticos.

\section{I- A sistematização das estratégias}

Após o término e gravação de cada reunião, foi realizada a transcrição das falas. Os debates sobre as situações-problema foram registrados em áudio e a transcrição dessas gravações, aliado às anotações da pesquisadora durante a coleta de dados, deu origem ao material de análise do estudo. Ao finalizar as transcrições das reuniões, tínhamos em mãos muitos dados. A análise que nos propusemos realizar demandou reorganização e categorização dos dados. Não era possível analisar os dados gerados pela confrontação das situações-problema em "estado bruto".

Iniciamos a análise de conteúdo da seguinte maneira: desmontamos a estrutura existente buscando suas características para extrair um novo significado. Gatti (2005) aconselha atenção às sequências de trocas e às condições contextuais das falas dos participantes do grupo focal. Segundo a pesquisadora, pode-se ter análises menos ou mais estruturadas, sem quebra ou com quebra das sequiências interacionais, ou ainda uma combinação de ambas as formas, para não cair em reducionismos nos quais somente a contribuição de cada indivíduo ou a interação do grupo é salientada. Nesta análise, optamos pela combinação de ambas as formas, privilegiando ora falas com intervalos, ora sequência de diálogos. 
O USO DE SITUAÇÕES-PROBLEMA como instrumento metodológico em uma pesquisa qualitativa no campo da Formação de professores

Seguindo as indicações de Bardin (2004), perpassamos três fases: a pré-análise dos dados (levantamento de hipóteses, leitura flutuante), a exploração do material e o tratamento dos resultados obtidos e interpretação. Durante a exploração do material, os dados brutos foram codificados, ou seja, transformados de maneira organizada e "agregados em unidades, as quais permitem uma descrição das características pertinentes do conteúdo" (Holsti apud BARDIN, 2004, p. 104). Os dados gerados pela transcrição das falas das professoras foram reorganizados em dimensões de análise utilizando uma combinação de falas com e sem quebra das seqüências de diálogo.

Chamou-nos a atenção o fato que as professoras se referiam às suas intervenções para as situações-problema como "estratégias":

Eu uso estratégias diversas. (Fabiana)

Eu acho que não tem estratégia única. (Maria)

Na minha sala eu tenho que pensar em algumas estratégias. (Cecília)

Algumas vezes eu consigo diversificar atividades, mas tem outras estratégias que são bacanas. (Taíssa)

É uma estratégia que eu adoto pra lidar com essa questão dos ritmos diferentes. (Lúcia)

O termo "estratégia" foi utilizado trinta e três vezes durante as reuniões, sem que a pesquisadora o introduzisse nas discussões. Segundo Morin (2000, p. 87), a estratégia

elabora um cenário de ação que examina as certezas e as incertezas da situação, as probabilidades, as improbabilidades (...). Para tudo que se efetua em ambiente instável e incerto, impõe-se a estratégia. Deve, em um momento, privilegiar a prudência, em outro, a audácia e, se possível, as duas ao mesmo tempo.

Se considerarmos as incertezas inerentes à complexidade da sala de aula e o uso do termo "estratégia" pelas professoras do Núcleo Básico do $\mathrm{CP}$, parece apropriado referirmo-nos às intervenções discutidas pelas docentes às situações-problema como "estratégias".

\section{II-A validação das estratégias de ensino por meio dos argumentos das docentes}

Por vezes, o que justificou a estratégia utilizada por uma professora foi a sua própria argumentação, outras vezes, foi a fala de outra professora que justificou sua proposição ou até mesmo os resultados de pesquisas. A concordância no grupo de professoras era manifestada por acenos de cabeça, murmúrios de aprovação, verbalizações, registros espontâneos etc. As estratégias de ensino sobre premiação e 
utilização de imagens para fomentar uma discussão em sala de aula não foram validadas pelas professoras e serão discutidas na análise. Algumas estratégias fomentaram posições discordantes com ou sem um consenso final e estas também foram incluídas na análise. Não foi identificada a troca de truques, caracterizados pela arbitrariedade, ilegalidade ou imoralidade de seu conteúdo.

a) A confrontação das estratégias com pesquisas empíricas

Após a validação das estratégias por meio da argumentação entre as professoras do Núcleo Básico do CP, confrontamos essas estratégias com os resultados de pesquisas científicas empíricas, que constituiu o terceiro passo do processo de validação. $\mathrm{O}$ movimento de interlocução entre os dados e a teoria não objetivou regular e corrigir os saberes trocados pelos professores, visou tampouco formular um "manual" de instruções com o registro dos saberes.

b) Saber Docente

Consideramos para a análise de dados saber como uma construção coletiva oriunda das trocas entre os agentes, baseado na racionalidade de natureza argumentativa (GAUTHIER et al., 2006) e os saberes docentes como um amálgama de saberes provindos de diversas fontes: a experiência da prática pedagógica, a formação acadêmica, a experiência escolar anterior etc. (TARDIF, 2002). O saber é ligado às exigências de racionalidade, de discursos e ações cujos sujeitos estão em condições de apresentar uma justificativa racional.

A definição de saber nessa concepção engloba os "argumentos, os discursos, as ideias, os juízos e os pensamentos que obedecem a exigências de racionalidade, ou seja, as produções, discursos e as ações cujo agente é capaz de fornecer os motivos que as justificam" (GAUTHIER et al., 2006, p. 336). A racionalidade de um discurso ou de uma ação é decidida por meio da comunicação entre agentes e sua capacidade de argumentação depende do contexto de interação e das razões alegadas pelos sujeitos do discurso.

Se observarmos o caminho inverso percebemos que o saber docente fundamenta as estratégias, ele é a base das práticas adotadas e trocadas entre as professoras. Lembramos que um saber não se reduz à extração de leis contidas em um objeto, ele é fruto de uma interação entre sujeitos, de uma interação lingüística inserida em um contexto. O saber remete a algo que é intersubjetivamente aceitável para as partes presentes e terá valor na medida em que permita manter aberto o processo de questionamento, capaz de alimentar a reflexão.

Elaboramos (Figura 1 e Figura 2) propostas de modelos onde podemos situar a análise de dados sobre os saberes docentes e as estratégias de ensino. A história de vida 
O USO DE SITUAÇÕES-PROBLEMA como instrumento metodológico em uma pesquisa qualitativa no campo da Formação de professores

das professoras, o contexto escolar onde trabalham, o currículo escolar e a formação acadêmica das docentes influenciam na elaboração dos saberes docentes, todos estes situados na História, na Cultura e na Sociedade. A Figura 1, traz uma representação gráfica desse modelo.

Figura 1: Esquema representativo dos saberes docentes e as estratégias de ensino

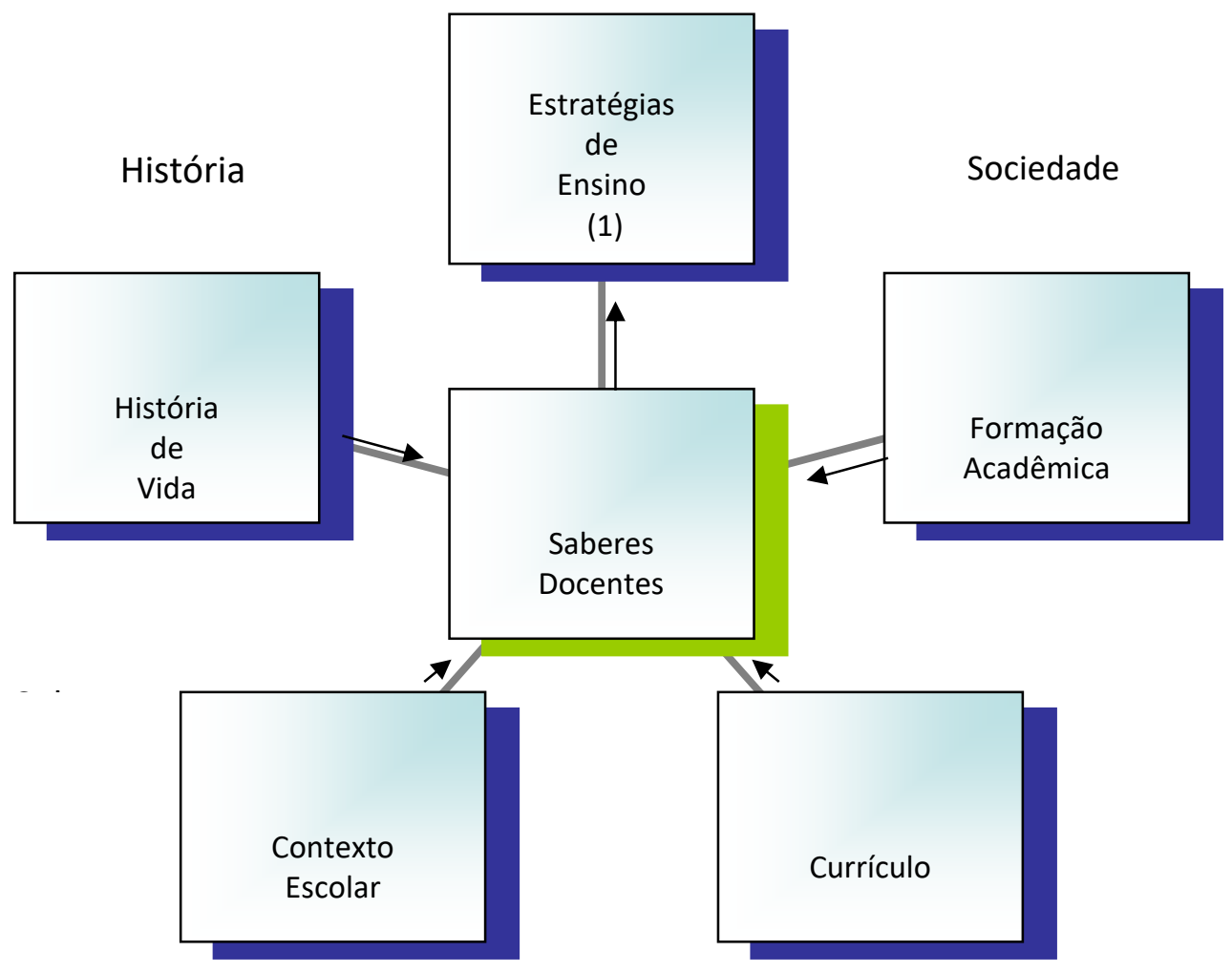

Fonte: SILVA (2009, p. 60).

Estes saberes docentes por sua vez, influenciam na criação e na troca de estratégias de ensino entre as professoras. "O saber para nós está enraizado numa comunidade de agentes, ele corresponde a diferentes tipos de juízo e seu objetivo é prático" (GAUTHIER et al., 2006, p. 340). Na Figura 2, temos a representação da troca de estratégias entre os professores. 
Figura 2: Esquema representativo da troca de estratégias de ensino entre docentes.

(1)

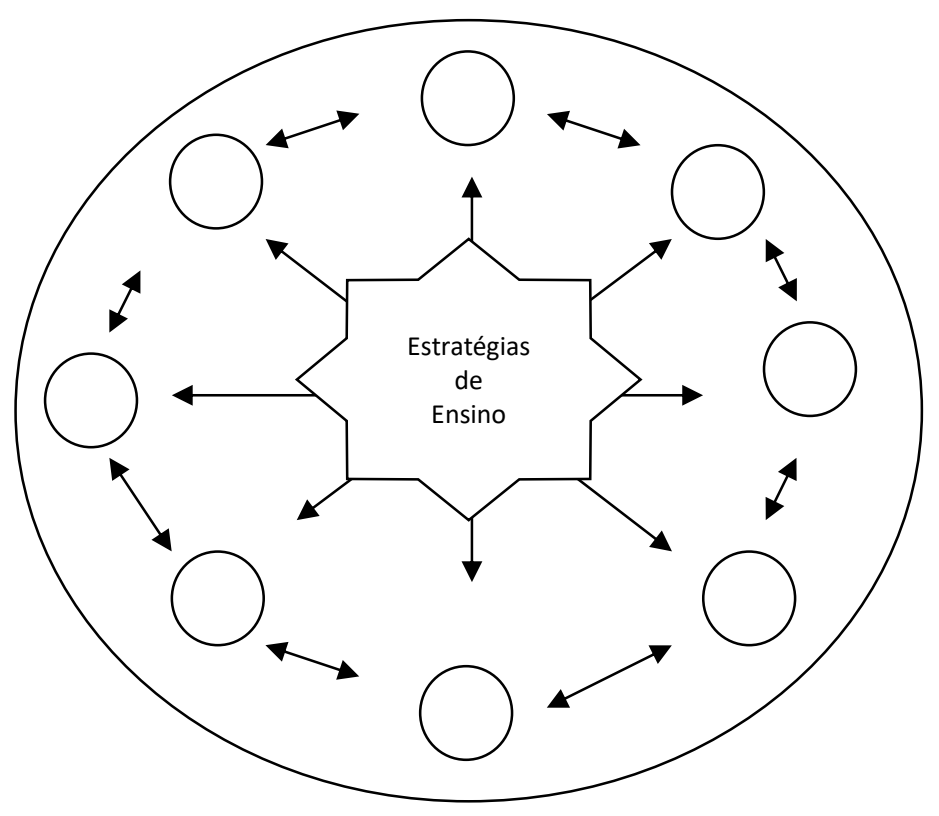

Fonte: SILVA (2009, p. 60).

As dimensões de análise foram definidas a posteriori, a partir do próprio material obtido. As unidades de análise emergiram das falas, do discurso, das trocas das professoras o que implicou em uma constante ida e volta ao material de análise. As discussões geradas a partir das situações-problema foram organizadas nas seguintes dimensões de análise: 1) organização do tempo, 2) organização do espaço, 3) organização da interação professora/alunos, 4) transgressões e incivilidades e 5) ritmos diferenciados.

A categorização acima é uma das possíveis tentativas de organização dos dados. Reconhecemos que outras são possíveis. Uma dificuldade em analisar os dados era que em muitos momentos havia a intercessão de uma categoria com outra. Por exemplo, quando uma fala sobre a categoria "ritmos diferenciados" estava sendo analisada, esta intercedia com a análise sobre "transgressões". Apesar de ser um desafio, tal característica demonstra que as situações-problema retratavam a prática pedagógica, pois nesta as interações em sala de aula, a organização dos tempos e espaços, as transgressões, a gestão dos conteúdos são indissociáveis. Qualquer separação entre gestão da matéria e gestão da classe, por exemplo, é artificial e realizada meramente para fins de análise da pesquisa.

As ações do ensino têm muitas faces: um franzimento de testa pode acompanhar uma pergunta; fazer entender um problema de matemática pode adentrar na gestão da classe, introduzindo, por exemplo, um novo modo de trabalho em equipe; uma transição da matéria requer manter a 
O USO DE SITUAÇÕES-PROBLEMA como instrumento metodológico em uma pesquisa qualitativa no campo da Formação de professores

atenção dos alunos etc. Em outros termos, é difícil dissociar o currículo real da gestão da classe e das atividades normativas ligadas à socialização dos alunos. Os professores de profissão raramente separam as duas coisas, e a sua preparação das aulas cobre simultaneamente esses dois aspectos, que são obrigados a assumir simultânea e integralmente em classe. (TARDIF, 2007, p. 218)

Gauthier e colaboradores (2006) como também Morin (2000), salientam a necessidade do uso da prudência na utilização e mobilização dos saberes pelos professores. Segundo os pesquisadores, o professor é um agente prudente, um profissional racional que toma decisões em situações de urgência. Nessa concepção os resultados de pesquisas não podem determinar a ação a ser empreendida, mas podem informá-lo.

\section{Concluindo: A discussão sobre situações-problema provou criar um espaço rico para trocas entre professores.}

A estratégia metodológica provou ser eficiente para os objetivos da pesquisa. As situações-problema organizadas a partir da experiência da pesquisadora, como professora iniciante, e apresentada ao grupo de professoras do Núcleo Básico/CP, exerceram papel importante como elementos instigadores da discussão. Por intermédio do instrumento metodológico, constatamos que um ambiente de trocas entre as professoras do Núcleo Básico foi criado. O fato da pesquisadora já ter participado daquele grupo como docente pode ter contribuído para o clima de descontração entre as professoras. Percebemos também um ambiente de apoio mútuo entre as professoras do Núcleo Básico durante a discussão das situações-problema, manifestado pela exposição de dúvidas e problemas e por falas como "Deixa eu te ajudar...". Ou nas falas das professoras Fabiana e Ludmila ao final da discussão de uma situação-problema:

- Falando das dificuldades fica mais fácil de partilhar do que quando a gente não diz delas, quando está tudo bem...

- Fabiana, ou então a gente pensa assim: só eu que não dou conta disso... Não vou falar para ninguém!

Por meio da discussão, as trocas entre as professoras foram objetivadas e, portanto, passíveis de serem pesquisadas. As professoras relataram como trabalhavam com aquelas situações na prática, ouviam e partilhavam experiências, dúvidas, sugestões etc. Foi criado um espaço de validação dos saberes por intermédio da discussão, do posicionamento de cada professora e da sua argumentação.

$\mathrm{Na}$ argumentação os interlocutores esforçam-se para superar os pontos de vista iniciais de sua subjetividade, elevando pretensões à validade intersubjetiva para seus propósitos ou ações (TARDIF e GAUTHIER, 2001, p. 194). 
O fomento da discussão entre professores com situações-problema é uma importante contribuição deste trabalho e pode vir a ser um instrumento interessante para cursos de formação inicial e/ou continuada de professores. Essa sugestão pode ser avaliada como pertinente ou não em futuras pesquisas educacionais.

\section{Referências}

BARDIN, L. Análise de Conteúdo. (3ª edição) Lisboa, Portugal: Edições 70, 2004.

COELHO, A. M. S.; DINIZ-PEREIRA, J. E. Olhar o magistério "no próprio espelho": O conceito de profissionalidade e as possibilidades de se repensar o sentido da profissão docente. Revista Portuguesa de Educação, v. 30, p. 7, 2017.

DINIZ-PEREIRA, J. E. A construção do campo da pesquisa sobre formação de professores. Revista FAEEBA, vol. 22, p. 145-154, 2014.

DINIZ-PERIERA, J. E. Formação de professores. Pesquisas, representações e poder. (2a edição) Belo Horizonte: Autêntica, 2006.

ENGUITA, M. F. A ambigüidade da docência: entre o profissionalismo e a proletarização. Teoria \& Educação, Porto Alegre, n. 4, 1991.

FIORENTINI, D.; SOUZA MELO, G. F. Saberes docentes um desafio para acadêmicos e práticos. In: GERALDI, C. et. al (org.). Cartografias do trabalho docente: professor(a)pesquisador(a). Campinas/SP: Mercado das Letras/ALB, 1998.

GATTI, B. A. Grupo Focal na pesquisa em Ciências Sociais e Humanas. Brasília: Líber livros, 2005.

GAUTHIER, C. et al. Por uma teoria da Pedagogia. Pesquisas contemporâneas sobre o saber docente. ( $2^{\mathrm{a}}$ edição) Rio Grande do Sul: Editora Unijuí, 2006

MORGAN, D. L. Focus groups as qualitative research. London: Sage, 1997.

MORIN, E. Os sete saberes necessário à Educação do futuro. São Paulo: Cortez UNESCO, 2000.

NÓVOA, A. Os professores e a sua formação. (2a edição) Lisboa: Dom Quixote, 1995.

SILVA, M. C. L. Saberes docentes e estratégias de Ensino: As trocas entre professores do ensino fundamental. Dissertação (Mestrado). Programa de Pós-Graduação em educação. PPGE/UFMG. Belo Horizonte, 2009.

SILVA, M. C. L.; DINIZ-PEREIRA, J. E. O uso de situações-problema como instrumento metodológico em uma pesquisa qualitativa no campo da formação de professores. In: Neide Cavalcante Guedes; Hilda Mara Lopes Araújo. (Org.). Alternativas metodológicas para a pesquisa científica. 1ed. Teresina: EDUFPI, 2017, v. 1, p. 79-104. 
O USO DE SITUAÇÕES-PROBLEMA como instrumento metodológico em uma pesquisa qualitativa no campo da Formação de professores

TARDIF, M. Saberes profissionais dos professores e conhecimentos universitários. Elementos para uma epistemologia da prática profissional dos professores e suas conseqüências em relação à formação para o magistério. In: Revista Brasileira de Educação, $\mathrm{n}^{\circ} 13,2000$.

TARDIF, M e GAUTHIER, C. O professor como "ator racional": que racionalidade, que saber, que julgamento? In: PERRENOUD, P. et al. Formando professores profissionais. Quais estratégias? Quais competências? (2a edição) Porto Alegre: Artmed, 2001.

TARDIF, M. Saberes docentes e formação profissional. Petrópolis: Editora Vozes, 2002.

VERLOOP, N. et al. Teacher knowledge and the knowledge base of teaching. International Journal of Educational Research. v. 35, 2001.

ZEICHNER, K. M. Para além da divisão entre professor-pesquisador e pesquisador acadêmico In: GERALDI, C. M.; FIORENTINI, D. \& PEREIRA, E. M. (orgs.) Cartografia do trabalho docente: professor(a)-pesquisador(a). Campinas: Mercado de Letras, 1998.

Recebido em: 21 mar. 2020.

Aprovado em: 21 mai. 2020.

* Mariana Costa Lopes da Silva é Mestre em Educação pela Universidade Federal de Minas Gerais (UFMG), onde licenciou-se em Pedagogia, é ainda especialista em Psicopedagogia (UEMG).

** Júlio Emílio Diniz-Pereira é Doutor em Educação pela Universidade do Estado de Wisconsin, em Madison, Estados Unidos. Professor do Programa de Pós-graduação em Educação da Universidade Federal de Minas Gerais (UFMG). Bolsista de Produtividade em Pesquisa do CNPq - Nível 2.

e-mail: juliodiniz@fae.ufmg.br

https://orcid.org/0000-0002-5401-4788 